\title{
Spatial Analysis of the Effects of Single- and Double-Bed Layouts on Patients' Communication Patterns and Psychological States in Dialysis Centers
}

\author{
Diyaliz Merkezlerinde Tek ve Çift Sıra Yatak Yerleșim Düzenlerinin Hastaların \\ Illetişim ve Psikolojik Durumları Üzerine Etkilerinin Mekânsal Analizi
}

DD Meryem YALÇIN, ${ }^{1}$ (1) Betül Bilge ÖZDAMAR ${ }^{2}$

ABSTRACT

The present study was aimed to examine the effect of the interior layouts in dialysis treatment centers (single-bed and double-bed layouts) on patients' communication and well-being. Spatial design of dialysis centers should be examined with respect to their functionality and effects on patients' psychological state. The interior bed layout in dialysis centers may influence patients' communication with other patients and healthcare staff as well as their spatial perception. This study was carried out in three dialysis centers in Ankara, Turkey, that had both single-bed and double-bed layouts in similar interior spatial conditions. Patients were randomly selected from these centers and 119 patients completed the questionnaire. The patients who received treatment in the single-bed layout had a more positive attitude towards the interior atmosphere; however, their interactions with healthcare staff and other patients were less than those who received treatment in the double-bed layout. Bed-row layout in dialysis centers has considerable effects on patients' communication, interaction with other patients and staff, and spatial perception. The present study thereby, provides insights into the criteria that need to be considered while designing treatment areas.

Keywords: Dialysis spatial design; patient communication requirements; single-double bed layout.

ÖZ

Bu çalışmada; diyaliz tedavi merkezlerinde tek yatak ve çift sıra yatak düzeni planlamasına göre yapılan iç mekân yerleşim planlarının, hasta iletişimi ve algısı üzerindeki etkisinin incelenmesi ve iç mekâna yönelik ilişki değerlerinin saptanması amaçlanmıştır. Diyaliz merkezlerinin mekân tasarımına yönelik işlevsel yaklaşımı ve mekânın kullanıcısı olan hastaların psikolojik durumu üzerindeki etkileri, algısal değerler üzerinden ele alınarak incelenmiştir. Diyaliz merkezlerinde uygulanan yatak düzeni planlamaları; hastaların diğer hastalar ve sağlık personeliyle olan iletişimi ile mekânsal algısını etkileme durum ve düzeyi açısından araştırılmıştır. Araştırma, Ankara'da iç mekân planlamasında hem tek hem de çift sıra yatak düzeni bulunan üç diyaliz merkezinde gerçekleştirilmiştir. Bu merkezlerden hizmet alan hastalar rastgele seçilmiş ve 119 hasta üzerinde anket çalışması yapılmıştır. Değerlendirmede; tek yataklı düzende tedavi gören hastaların, çift yataklı düzende tedavi gören hastalara göre iç mekân atmosfer algısı açısından daha olumlu, ancak sağlık personeli ve diğer hastalar ile etkileşimleri açısından daha olumsuz bir algıya sahip oldukları ortaya çıkmıştır. Elde edilen veriler doğrultusunda; diyaliz merkezleri iç mekân planlamasında yer alan yatak düzenlerinin, hastaların iletişimi ile diğer hastalar ve sağık personeliyle olan etkileşimleri açısından, kullanıcıların mekân algısı üzerinde önemli etkilerinin olduğu ortaya konmuştur.

Anahtar sözcükler: Diyaliz mekân tasarımı; hasta iletişim gereksinimleri; tek-çift sıra yatak yerleşimi.

'Department of Interior Architecture and Environmental Design, Tobb University of Economics and Technology Faculty of Architecture and Design, Ankara, Turkey

${ }^{2}$ Department of Interior Architecture and Environmental Design, Başkent University Faculty of Fine Arts, Design and Architecture, Ankara, Turkey

Article arrival date: November 09, 2019 - Accepted for publication: January 24, 2021

Correspondence: Meryem YALÇIN. e-mail: myalcin@etu.edu.tr

○ 2021 Yıldız Teknik Üniversitesi Mimarlık Fakültesi - @ 2021 Yıldız Technical University, Faculty of Architecture 


\section{Introduction}

Ulrich's theory of supportive design states that care environments assist patients in coping with potential stress and in promoting healing (Ulrich, 1997, 1999). Supportive design theory assumes that these environments offer calming, stress-relieving, and health-enhancing properties for patients (Ulrich, 1997, 1999; Devlin, 2015). Several other major theories also support these conclusions. Antonovskys's $(1991,1997)$ "salutogenesis" focuses on factors that support human health and well-being. This theory stresses that a sense of coherence stimulates emotion and experience, both of which directly relate to patients' psychosocial statuses that are influenced by comprehensibility, manageability, and meaningfulness. Dilani $(2000,2001)$ translates components of these theories into environmental design factors that influence patients' psychosocial states and ability to cope with stress. Moreover, studies of therapeutic architecture examine built environments within a people-centered framework (Chrysikou, 2014). Shepley $(2005,2006)$ presents an evidence-based approach that examines the interactions between spatial elements and people's physiological and psychological states and accounts for these interactions in design. Thus, many case studies and current articles suggest that environmental design impacts patients' recovery and wellness (Schreuder et al., 2016; Alfonsi et al., 2014; Andrade et al., 2013; Connellan et al., 2013; Bartley, et al., 2010).

Healing environments designed to promote physical well-being through science and technology reflect the incontrovertible relationship between these two disciplines and can also foster psychological wellbeing in addition to physical recovery (Fottler, 2000; Milburn, 2001; Glanz, Rimer, \& Viswanath, 2008; Andrade et al., 2013; Connellan et al., 2013). Therefore, physical, mental, and psychological demands should be considered when designing hospital and recovery spaces to cultivate a positive and stimulating atmosphere (Yıldırım \& Yalcin, 2016; Ulrich, 2003; Kimmel, 2000; Parker \& Coiera, 2000). Supportive design that considers the strong link between interior spatial elements and psychological effects is needed to achieve positive effects such as contentment, constructiveness, gratification, and relaxation in healing environments (Dutta, 2008; Daft, 2001; Bordelon, 2001; Coiera \& Tombs, 1998).

The relationship between patient care and healing environments has already been explored within the context of dialysis centers. These treatment centers play an important role in patients' recovery and wellbeing as patients spend long periods of times in these environments (Dutta, 2008; Daft, 2001; Bordelon, 2001; Kimmel, 2000; Parker \& Coiera, 2000). This study aims to examine the effects of the bed-row layout and spatiality of dialysis centers on patients' wellbeing and communication, focusing on patients' interactions, spatial perception, and psychosocial development during treatment. The spatial design of dialysis centers and its effects on patient welfare have not been studied in terms of the bed-row layout's impact on patients' communication. Regarding the relationship between patients' behavioral patterns, expectations, and utilization of space during their routine visits, "supportive environments" positively influence patients' experiences and treatment satisfaction (Francis \& Glanville, 2001; Lawson \& Phiri, 2000). Patients coping with chronic kidney disorders may benefit from supportive spatial designs in that the built environment may improve their behavioral management.

The severity of kidney disorders varies and affects people regardless of age; thus, dialysis may become inevitable for some individuals (Polaschek, 2003; Welch \& Austin, 2001). Dialysis patients generally receive periodical treatment three times per week. This frequency necessitates an assessment of the effects of the space itself on patients' psychological states (Krueger, 2007). According to Ulrich (2004), the curative aspects of interior layouts include their cozy, comfortable, and flexible atmosphere for both caregivers and patients, regardless of the time of day. Many studies have stated that healthcare environments must consider curative design criteria when evaluating spatial quality (Chrysikou, 2014; Shepley, 2006, 2005; Ulrich, 2004. However, no studies have specifically addressed how bed-row layout affects communication and patients' perception of "session unity" (a sense of sustainable communication between patients and the staff of centers they frequently visit) in dialysis centers.

Case studies and current articles have shown that patients who are able to express their demands, impart information to their healthcare provider, and exchange opinions with other patients tend to experience the most positive treatment outcomes and therefore experience more positive physical and psychological effects (Chrysikou, 2014; Shepley, 2006, 2005). In other words, if patients have satisfactory perceptions of a space, it will ensure a positive experience for them (Glanz et al., 2008). These psychological benefits may increase the commitment to the ongoing treatment at dialysis centers. Likewise, spatial layout design that encourage communication may mitigate negative feelings, such as patients' sense that they have lost control of their life, body, or experiences (Ulrich, 2003). Correspondingly, the interior spatial layout of treatment centers should account for this variation in experience to maintain favorable results for patient wellness (Alfonsi, Capolongo, \& Buffoli, 2014; Pati et al., 2008). In other words if the bed row provides visual and/or 
verbal contacts around patients, doctor and/or healthcare staff, it will support patient relief procedures.

With the information derived from the literature mentioned above and the case studies it can be clearly stated that providing a spatial design which creates the opportunity for healthy communication is important in dialysis centers, and an appropriate bed-row layout can greatly enhance patients' experiences and treatment. Thus, this paper is examining the impact of bed-row layouts on patients' behavioral and physiological states, spatial perceptions, and opportunities for communication with other patients and healthcare staff. Receiving treatment in two possible dialysis center bed-row layouts-single bed and double bed-impacts patients' communication with other patients and healthcare staff and perceptions of treatment spaces in a dialysis center impact patients' communication with other patients and healthcare staff.

\section{Relationships Between Dialysis Patients'}

\section{Communication and Dialysis-Facility Layout}

Several types of relationships exist, characterized by emotional, informational, instrumental, and evaluative aspects in dialysis centers. Opportunities for communication provide patients with social interaction and relaxation (Koivula, Paunonen-Ilmonen, Tarkka, \& Laippala, 2002; Parker \& Coiera, 2000; Kimmel, 2000). Social and communicational requisites may be met in a dialysis center through the interior spatial layout (Connellan et al., 2013). Bed-row layout can influence patients' ability to communicate and their spatial perceptions, which can reduce physical and psychological isolation and lead patients to feel safer and more secure (Chrysikou, 2014; Chua, 2013; Parker \& Coiera, 2000; Kimmel, 2000). Increasing patients' feeling of safety reduces their anxiety and fear during treatment. Single, double, L-shaped, or U-shaped dialysis-unit layouts each have advantages and disadvantages; however, it is important for patients to be in a supportive group space, regardless of layout (Krueger, 2007; Polaschek, 2003; Welch \& Austin, 2001). So, research on other healthcare facilities has revealed the impacts of interior layouts on patient psychology and socialization, and designers which their facilities develop interior architectural plans with consideration of the relationships mentioned above (Chrysikou, 2014; Chua, 2013). Designers should pay sufficient attention to the degree of privacy offered to patients, as it is just as important for patients to exercise agency in communication. For example, some patients may choose not to communicate with anyone and may experience any lack of control over the degree of contact as a stress-boosting factor (Chua, 2013; Krueger, 2007). As such, bed-row and dialysis-unit layouts must complement each other; the layout must not only be functionally adequate, but also be conducive to communication and comfort alike.
The preliminary unstructured interviews conducted for this study demonstrate that patients' frequency and usage of dialysis spaces may play a decisive role in patients' location within the space, spatial perceptions, and interactions with staff, other patients, and visitors (psychosocial relations).

This study specifically examined how single- and doublebed layouts impacted patient-space relations in dialysis centers in terms of the effects of interior spatial allocation on patients' communicative behavior were assessed based on these two bed-row layouts. The preliminary research questions were developed from data gathered in a literature review along with unstructured interviews conducted with doctors, health care staff, and patients. The information obtained from these interviews regarding the effects of spatial design and bed-row layout in dialysis centers on patient communication is explained in detail below.

\section{Methodology}

\section{Preliminary Data: Unstructured Interviews}

Before the main activities of the study, patients, treatment units, and dialysis center spaces were observed and patients' and health care staffs were randomly interviewed between 2017-2018 in Gazi University Hospital, Ankara. Doctors, nurses, and other healthcare staff were asked about the elements including the functional, psycho-social, and atmospheric aspects of the interior space and the requirements of treatment units and patients. In addition, they were asked to suggest qualities of a supportive interior space. Based on the collected interview data, a survey (described below) was conducted.

The data acquired through unstructured interviews with doctors, nurses, and other healthcare staff are as follows:

Patients receive dialysis treatment three times per week for four hours each day. They spend twelve hours attached to the dialysis units. Thus, two significant factors regarding space usage in dialysis centers are recognized as integral components of "session unity":

- Patients prefer to receive treatment in a group, in the same space and time period each time.

- Patients prefer to receive treatment with the same patients, nurse, and bed as their previous sessions.

Consequently, the treatment period serves as a social activity that is similar to a group therapy.

Below are preliminary data from the unstructured interviews:

- Individuals prefer some verbal and visual communication with other patients in dialysis centers. 
- Verbal and visual communication are factors in the healing process that patients undergo for their challenging treatment.

- Interactions among patients fulfill their need for socialization, thereby positively affecting their psychological state.

- Though familiarity with the facility adds to patients' feelings of security, they also prefer to be treated by the same staff, in the same bed, and with the same dialysis machine as in their previous sessions.

- Patients define their personal zones by choosing the same bed and machine. Thus, it is important to maintain communication with the staff when trying to address this stated need.

\section{Problem Statement}

Dialysis centers are psychologically stressful places. Thus, their effects on patients' psychological states must be thoroughly examined. The need for communication in dialysis centers is significant and could be influenced by interior spatial design. The needs in question may directly relate to the location of the patient in the treatment room and the bed-row layout.

\section{Hypotheses}

The survey questions were constructed to seek answers to the following hypotheses:

$\mathrm{H} 1$ : Patients who receive treatment in a single-bed layout have fewer interactions with other patients than those who receive treatment in a double-bed layout.

$\mathrm{H} 2$ : There is a correlation between the number of bed rows where the treatment is carried out and patients' communication levels.

H3: The interior bed-row layout where treatment occurs within dialysis centers contributes to patients' feelings of familiarity.

H4: Patients' space perceptions differ between singlebed and double-bed layouts.

\section{Sampling Group}

This study examined the experiences of dialysis patients who received treatment at three centers with both singleand double-bed layouts between 2017 and 2018. Each treatment center exhibited equivalent interior spatial conditions to ensure that the effects of the bed-row layouts on patient perceptions were measured. Respondents were randomly selected from patients of three dialysis centers located in different regions in Ankara, Turkey. The dialysis centers serve different income groups; thus, our sample is representative of different income strata. The questionnaire was completed by 119 respondents.

\section{Research Setting}

Three research settings were selected for examination. The treatment environments with single- and doublebed rows in each dialysis center had equivalent interior environments (atmosphere, lighting, window size, furniture, and material) (Figure 1). The patient beds face

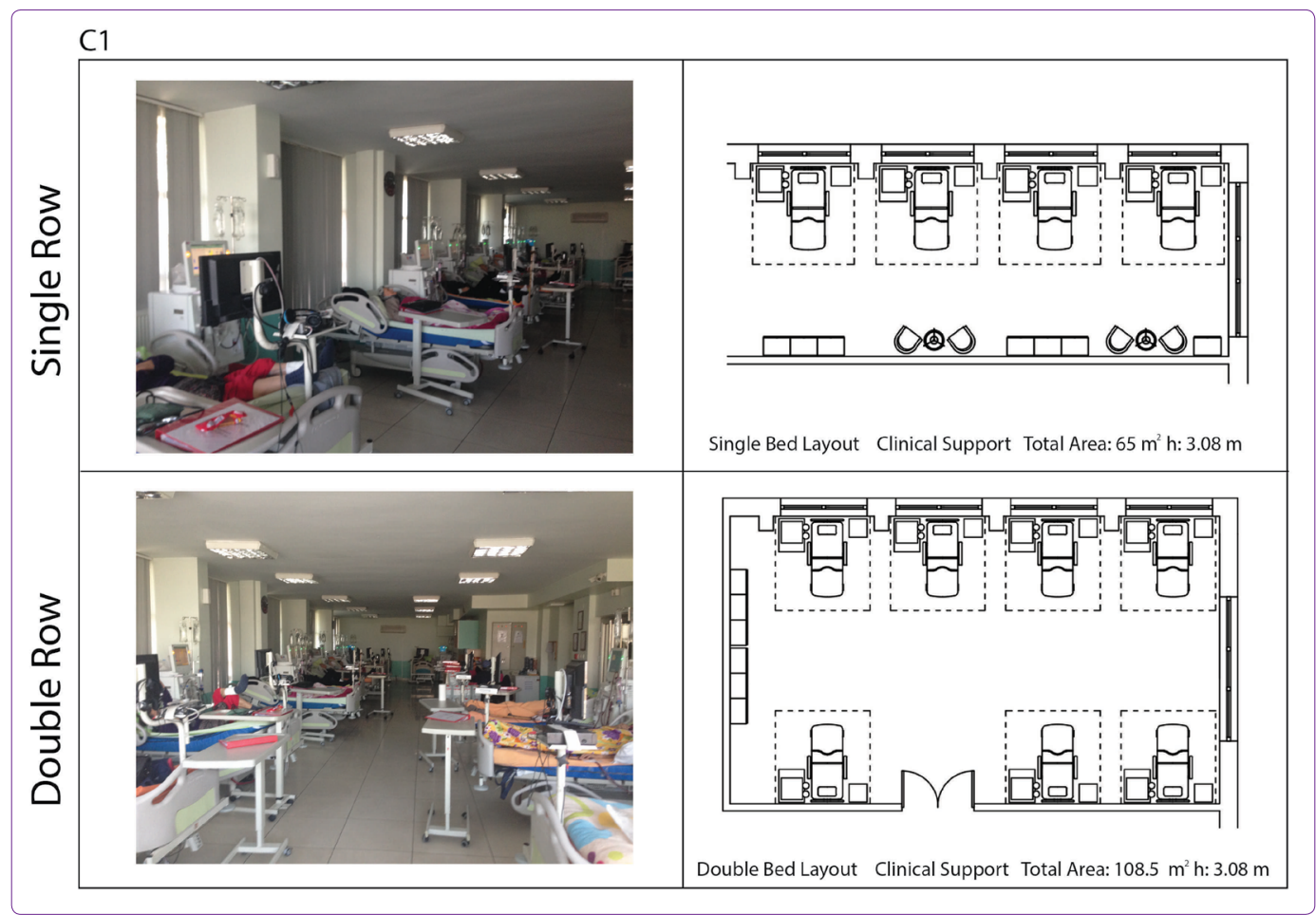

Figure 1. C1'Spatial Layout of single-doble bed treatment rooms. 
the wall in a single-bed layout, while they face each other in a double-bed layout (Figure 2). Details such as lighting, color, materials, and accessories have significant effects on patients' perception and evaluation of an interior space (Ulrich, 1992, 1991; Malkin, 1992).
The patient rooms used as research environments were selected for comparative analysis due to their similar plans and physical characteristics (i.e., daylight, artificial light, and air temperature) to ensure consistency in measuring the differential effects of interior design elements

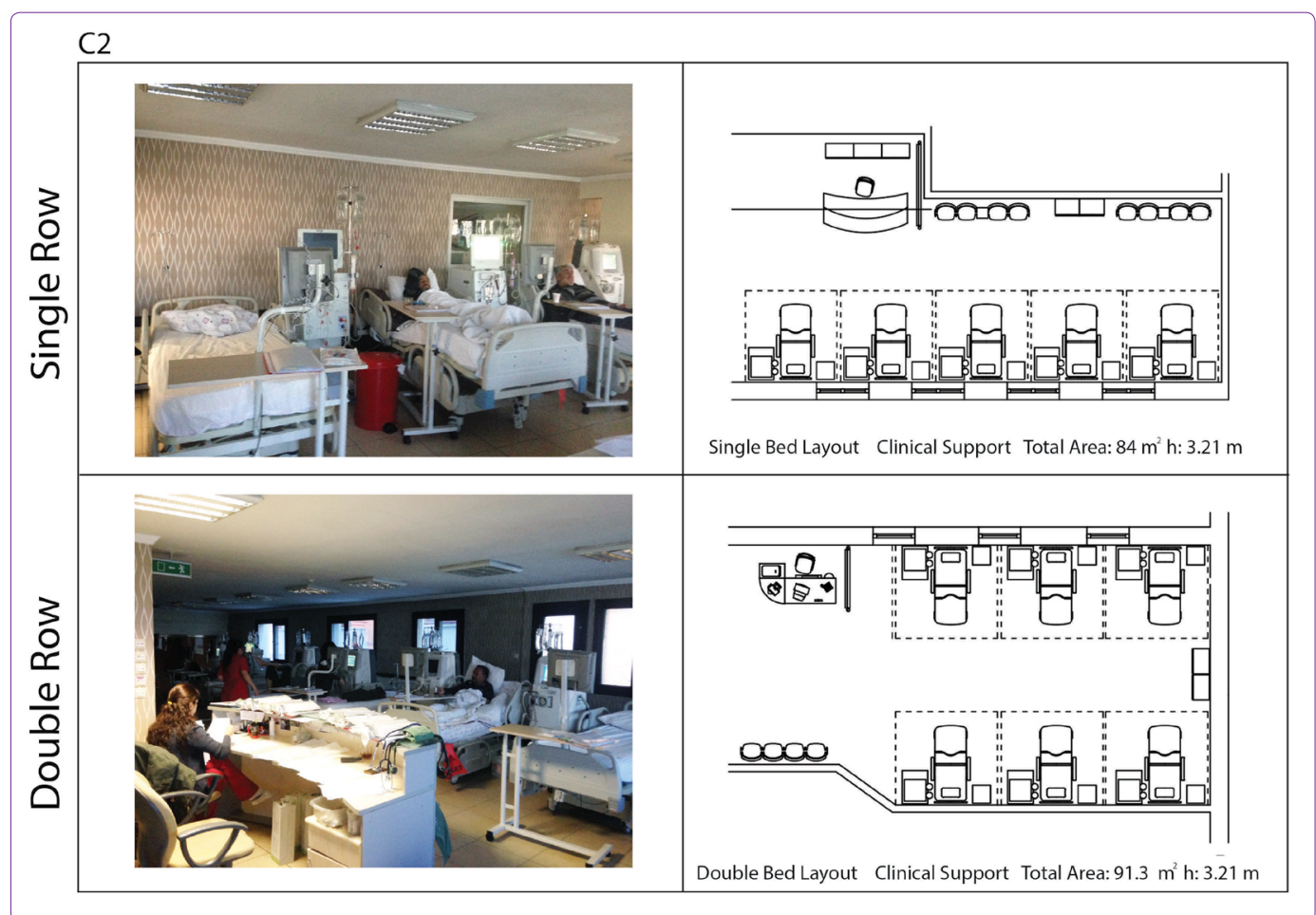

Figure 2. C2'Spatial Layout of single-doble bed treatment rooms.

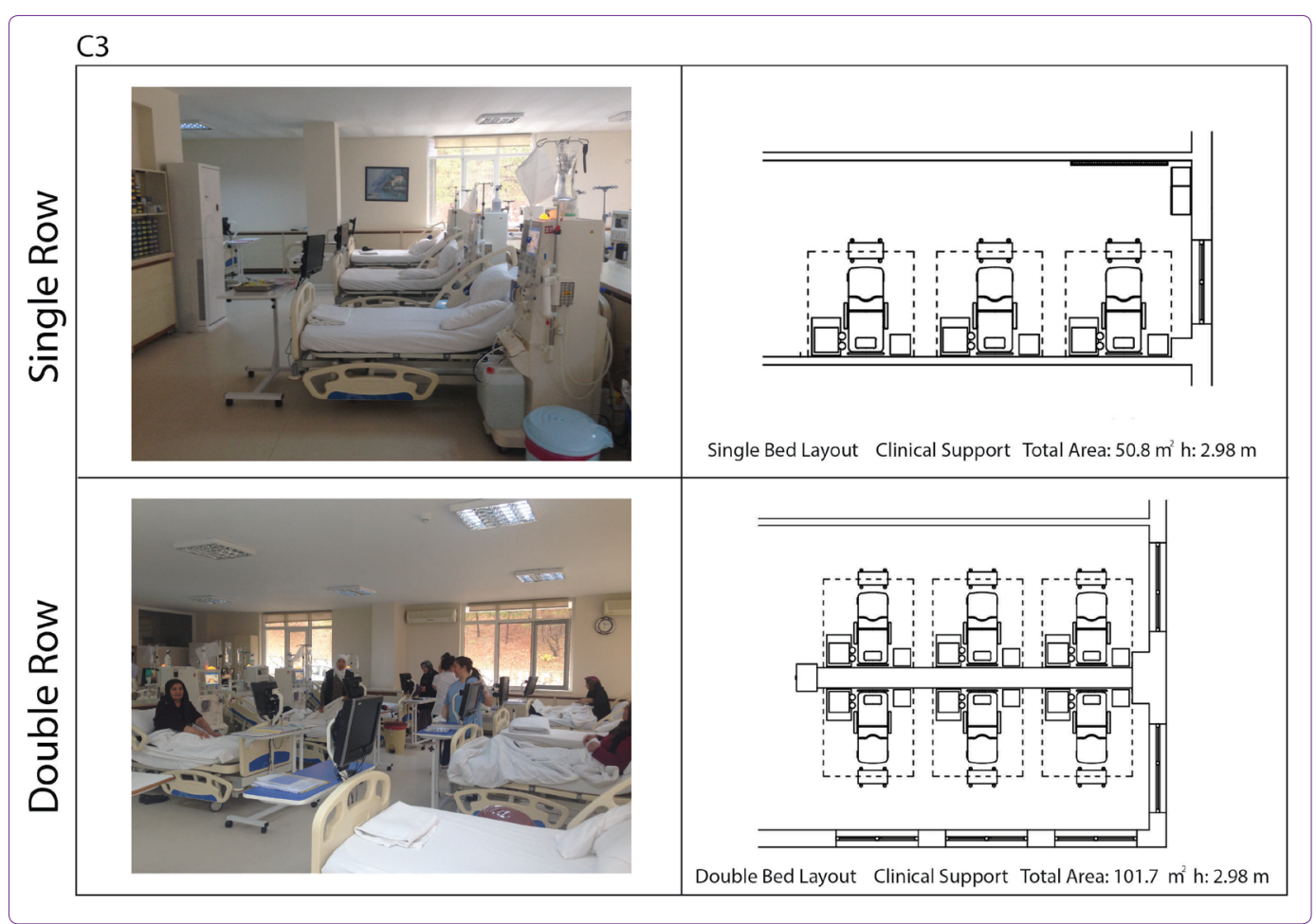

Figure 3. C3'Spatial Layout of single-doble bed treatment rooms. 
(i.e., room size and bed number) accurately (Table 1 ). Therefore, patients from each of the three treatment centers experience similar physical conditions and spatial qualities; the only appreciable difference is that they are treated in either single- or double-bed layouts.

These centers (C1, C2, and C3) were selected from around 30 dialysis centers in Ankara, Turkey. Because only these three treatment centers had equivalent atmospheric (lighting, furniture, finishing and materials) interior spatial conditions for making comparisons about the patients' communication requirements. As the aim was to compare the effects of two different bed-row arrangements on patients' perception, the interior space and design needed to be as similar as possible; the main difference needed to be the bed-row layout. C1, C2 and C3 were chosen because each had treatment rooms with single- and double-bed layouts that were quite similar in terms of atmosphere, lighting, window sizes, furniture, and material (Figure 1-3). Other dialysis centers had either one type bed-row layouts or very different atmospheric properties, therefore it was impossible to make comparison about their bedrow layout accurately.

The single and double-bed row layouts of treatment rooms in C1, C2, and C3 are shown below, respectively.

Table 1. Technical Comparisons of Single-Double bed C1, C2 and C3' treatment rooms

\begin{tabular}{|c|c|c|c|}
\hline & Similar Conditions & Single-Bed Layout & Double- Bed Layout \\
\hline \multirow[t]{11}{*}{$\mathrm{C} 1$} & Location & South-West (Noon and Afternoon Sun Light) & South-West (Noon and Afternoon Sun Light) \\
\hline & Lighting & General Lighting & General Lighting \\
\hline & & 4x18W Surface Mounted Double Parabolic & 4x18W Surface Mounted Double Parabolic \\
\hline & & Reflective Lighting Fixtures & Reflective Lighting Fixtures \\
\hline & & Snow White Fluorescent & Snow White Fluorescent \\
\hline & & Luminous Flux: 1000 Lumens & Luminous Flux: 1000 Lumens \\
\hline & & Color Temperature: $12000 \mathrm{~K}$ & Color Temperature: $12000 \mathrm{~K}$ \\
\hline & Window Size & Through Window & Through Window (One Side) \\
\hline & Atmosphere & Same Wall, Floor, Ceiling, Furniture & Same Wall, Floor, Ceiling, Furniture Color and Materia \\
\hline & (Color and Material) & Color and Material & \\
\hline & Bed Units & Equivalent & Equivalent \\
\hline \multirow[t]{11}{*}{$\mathrm{C} 2$} & Location & North (Day Light) & North-East (Day Light) \\
\hline & Lighting & General Lighting & General Lighting \\
\hline & & 4x18W Surface Mounted Double Parabolic & 4x18W Surface Mounted Double Parabolic \\
\hline & & Reflective Lighting Fixtures & Reflective Lighting Fixtures \\
\hline & & Snow White Fluorescent & Snow White Fluorescent \\
\hline & & Luminous Flux: 1000 Lumens & Luminous Flux: 1000 Lumens \\
\hline & & Color Temperature: $12000 \mathrm{~K}$ & Color Temperature: $12000 \mathrm{~K}$ \\
\hline & Window Size & $120 * 200$ & $120 * 200$ \\
\hline & Atmosphere & Same Wall, Floor, Ceiling, & Same Wall, Floor, Ceiling, \\
\hline & (Color and Material) & Furniture Color and Material & Furniture Color and Material \\
\hline & Bed Units & Equivalent & Equivalent \\
\hline \multirow[t]{11}{*}{$\mathrm{C} 3$} & Location & East (Morning Sun Light) & East (Morning Sun Light) \\
\hline & Lighting & General Lighting & General Lighting \\
\hline & & 4x18W Surface Mounted Double Parabolic & 4x18W Surface Mounted Double Parabolic \\
\hline & & Reflective Lighting Fixtures & Reflective Lighting Fixtures \\
\hline & & Snow White Fluorescent & Snow White Fluorescent \\
\hline & & Luminous Flux: 1000 Lumens & Luminous Flux: 1000 Lumens \\
\hline & & Color Temperature: $12000 \mathrm{~K}$ & Color Temperature: $12000 \mathrm{~K}$ \\
\hline & Window Size & $90 * 280$ & $90 * 280$ \\
\hline & Atmosphere & Same Wall, Floor, Ceiling, Furniture & Same Wall, Floor, Ceiling, Furniture \\
\hline & (Color and Material) & Color and Material & Color and Material \\
\hline & Bed Units & Equivalent & Equivalent \\
\hline
\end{tabular}




\section{Limitations}

The primary limitation of this study is the research environment. Three suitable dialysis centers $(C 1, C 2$, and C3) were found that had equivalent or similar interior spatial conditions. To compare patients' communication levels with other patients, doctors, and healthcare staff, the interior spatial conditions of the research environments had to be as similar as possible. In addition, centers C1, $\mathrm{C} 2$, and C3 each had both single and double bed-rows, while most dialysis centers had only one type of bedrow layout in their treatment rooms. However, patient responses to only two types of the many possible bed-row arrangements (single and double) could be compared in our research settings.

\section{Questionnaire Design}

In interviews with doctors, healthcare staff, and patients, it was determined that interaction among patients and staff and their treatment in common sessions (session unity) had positive psychological effects on patients in 2017-2018, Ankara. This study aimed to assess the effects of the bed-row layout on the patients during the 3-4 hours treatment sessions, and the questionnaire aimed to understand the relationship between the bed layouts experienced by patients and positive treatment outcomes.

Thus, the questionnaire evaluated five areas: patient demographics, spatial conditions of the dialysis center, functionality and bed-row layout of dialysis center treatment spaces and their effect on communication among patients and healthcare staff, patients' communication behavior, and patients' perception of treatment spaces.

\section{Evaluation of the Data}

In this study, the independent variable was the assessment of single and double bed-row layout in each dialysis center. The dependent variables were spatial characteristics of the dialysis center (i.e., number of beds and dimensions), functional characteristics of the dialysis center (i.e. layout, daylight, and health staff desk), patients' communication with other patients and healthcare staff (i.e. visual communication, familiarity, or place attachment), and space perception characteristics of the dialysis center (i.e. spaciousness, comfort level, etc.). Cronbach's alpha was analyzed to test the reliability of the measurement instrument. To test the hypotheses and analyze the relationships between the dependent and independent variables, an independent t-test and Pearson's chi-square test were performed. Statistically significant data have been expressed graphically for each dependent and independent variable.

\section{Results}

Based on the data collected from the three dialysis centers and the analysis of a total of 119 questionnaires, the test distribution was normal. The Cronbach's alpha of the questionnaire (which measured spatial characteristics, functional characteristics, patients' communication, and patients' space perceptions) was 0.821 , indicating a high level of internal consistency.

The first part of the questionnaire included questions about patient demographics, the results of which are shown in Table 2. The sample consisted of 51 female and 68 male patients, and most patients were over 40 years old. Among the 119 participants, only one was 18-25 years old $(N=119, S D=0.973)$. Table 1 shows the number of treatments received in a week; most patients received three per week. Regarding patients' education levels, $33.6 \%$ of the patients had graduated from middle school, $25.2 \%$ from high school, and $24 \%$ from university.

The single-bed layout was preferred by 58 patients, while the double-bed layout was preferred by 61 patients. Female patients tended to prefer the double-bed layout while male patients tended to prefer the single-bed layout when they received treatment. The difference value of female patients' preference for the double-bed layout and that of male patients for the single-bed layout had more higher responses than males when they received treatment (Table 3).

The statistical relationships of the bed-row layout (single or double) with gender groups (male, female) and

Table 3. Patient's communication

\begin{tabular}{lccccc}
\hline Bed Layout & N. & Female & Male & Mean & Std. Dev. \\
\hline Single & 58 & 20 & 38 & 3.36 & 0.788 \\
Double & 61 & 31 & 30 & 3.54 & 0.848 \\
\hline
\end{tabular}

Table 2. Demographic characteristics

\begin{tabular}{|c|c|c|c|c|c|c|c|c|c|c|c|c|c|c|c|c|c|c|c|c|c|c|c|}
\hline \multicolumn{10}{|c|}{ Age } & \multicolumn{4}{|c|}{ Gender } & \multicolumn{10}{|c|}{ Education } \\
\hline \multicolumn{2}{|c|}{$18-25$} & \multicolumn{2}{|c|}{$26-35$} & \multicolumn{2}{|c|}{$36-45$} & \multicolumn{2}{|c|}{$46-55$} & \multicolumn{2}{|c|}{$56+$} & \multicolumn{2}{|c|}{ Female } & \multicolumn{2}{|c|}{ Male } & \multicolumn{2}{|c|}{ Primary } & \multicolumn{2}{|c|}{ Secondary } & \multicolumn{2}{|c|}{ High } & \multicolumn{2}{|c|}{ University } & \multicolumn{2}{|c|}{ Gard } \\
\hline $\mathbf{F}$ & $\%$ & $\mathbf{F}$ & $\%$ & $\mathbf{F}$ & $\%$ & $\mathbf{F}$ & $\%$ & $\mathbf{F}$ & $\%$ & $\mathbf{F}$ & $\%$ & $\mathbf{F}$ & $\%$ & $\mathbf{F}$ & $\%$ & $\mathbf{F}$ & $\%$ & $\mathbf{F}$ & $\%$ & $\mathbf{F}$ & $\%$ & $\mathbf{F}$ & $\%$ \\
\hline 1 & 0.008 & 9 & 7.5 & 38 & 31.9 & 37 & 31.1 & 34 & 28.6 & 51 & 42.9 & 68 & 57.1 & 17 & 14.3 & 40 & 33.6 & 30 & 25.2 & 29 & 24.4 & 3 & 2.5 \\
\hline
\end{tabular}


spatial characteristics were analyzed. Table 3 shows the mean, standard deviation, and t-value for each dependent variable item.

Table 3 shows the spatial characteristics of the dialysis centers. Based on the means and t-values, patients exhibited more positive perceptions of the spatial attributes of the double-bed layout than the single-bed layout. Two groups of patients were analyzed to measure the effect of spatial characteristics on their verbal or/and visual communication. The commination opportunities of the treatment space were statistically significant higher in the double-bed layout, indicating that patients in a doublebed setting are more likely to communicate (Table 4).

Furthermore, compared to female patients, male patients have a more positive perception of most discrete attributes of both the single- and double-bed layouts. The statistical relationships of bed-row layouts (single, double) with gender groups (male, female) and subjects' psychosocial interaction attributes were analyzed. Table 4 shows the mean, standard deviation, and t-value for each dependent variable item.

The statistical relationships regarding patients' communication statuses were analyzed. Participants indicated that they mostly communicated with the healthcare staff and expressed that they were satisfied staff's prompt responses in most cases. Communication between patients received low ratings $(M=1.99, S D=0.83)$, and socialization with other patients was significantly lower in the single-bed layout compared to the double-bed layout $[\mathrm{t}(39)=4.397, \mathrm{p}=0.009]$. This finding supports the first and third hypotheses: patients who receive treatment in a single-bed layout communicate less with healthcare staff and other patients than patients who receive treatment in a double-bed layout do. In addition to this finding, there is a (positive) linear relationship between treatment in the double-bed layout and socializing with other patients (Pearson's correlation coefficient $=0.239$, $\mathrm{p}=0.009$ ) (Table 4).

Inter-patient socialization is supported by a doublebed layout. The statistical relationships of the dialysis unit layout (single, double) with gender groups (male, female) and subjects' spatial perception attributes were analyzed. The mean, standard deviation, and t-value for each dependent variable item. Overall, participants found their treatment space comfortable ( $M=3.94, S D=0.63$ ) (Table 6).

There is a positive linear relationship between the single-bed layout and comfort level (Pearson's correlation coefficient $=0.214, p=0.019$ ). Patients who received treatment in the single-bed layout felt more comfortable than those treated in the double-bed layout. This finding

Table 4. Space characteristics of dialysis centers

\begin{tabular}{|c|c|c|c|c|}
\hline \multirow[b]{3}{*}{ Dependent variables } & \multicolumn{2}{|c|}{ Layout } & \multicolumn{2}{|c|}{ Gender } \\
\hline & Single Row & Double Row & Male & Female \\
\hline & Mean (SD) & Mean (SD) t-Value & Mean (SD) & Mean (SD) t-Value \\
\hline Size of the room & $3.63(0.85)$ & $3.44(0.94)-1.185$ & $3.54(0.85)$ & $3.52(0.93)-0.117$ \\
\hline Height of the room & $3.51(0.75)$ & $3.65(0.62)-1.089$ & $3.60(0.63)$ & $3.57(0.73)-0.266$ \\
\hline Number of the beds & $3.48(0.68)$ & $3.62(0.71)-1.097$ & $3.47(0.64)$ & $3.61(0.73)-1.140$ \\
\hline Number of the dialysis $\mathrm{m}$. & $3.53(0.75)$ & $3.54(0.69)-0.49$ & $3.41(0.66)$ & $3.63(0.75)-1.661$ \\
\hline Socialization & $3.37(0.79)$ & $3.75(0.4)-2.662^{*}$ & $3.52(0.83)$ & $3.60(0.75)-0.503$ \\
\hline Comfort level & $3.81(0.60)$ & $4.08(0.64)-2.375^{*}$ & $3.98(0.61)$ & $3.92(0.65)-0.456$ \\
\hline
\end{tabular}

Table 5. Patients' psycho-social interaction

\begin{tabular}{|c|c|c|c|c|}
\hline \multirow[b]{3}{*}{ Dependent variables } & \multicolumn{2}{|c|}{ Layout } & \multicolumn{2}{|c|}{ Gender } \\
\hline & Single Row & Double Row & Male & Female \\
\hline & Mean (SD) & Mean (SD) t-Value & Mean (SD) & Mean (SD) t-Value \\
\hline Other patient & $1.96(0.99)$ & $2.01(0.67)-0.330$ & $2.05(0.91)$ & $1.90(0.72)-1.010$ \\
\hline Health staff & $1.86(1.01)$ & $1.88(0.98)-0.126$ & $1.73(0.97)$ & $2.05(1.00)-1.769$ \\
\hline Place attachment & $3.29(0.78)$ & $3.44(0.90)-0.883$ & $3.41(0.90)$ & $3.31(0.88)-0.592$ \\
\hline Visual com. & $3.86(0.63)$ & $3.94(0.53)-0.459$ & $3.88(0.50)$ & $3.94(0.71)-0.743$ \\
\hline Social interaction & $3.36(0.76)$ & $3.95(0.61)-4.605$ & $3.69(0.73)$ & $3.62(0.77)-0.457$ \\
\hline
\end{tabular}


Table 6. Space perception of dialysis centers

\begin{tabular}{|c|c|c|c|c|}
\hline \multirow[b]{3}{*}{ Dependent variables } & \multicolumn{2}{|c|}{ Layout } & \multicolumn{2}{|c|}{ Gender } \\
\hline & Single Row & Double Row & Male & Female \\
\hline & Mean (SD) & Mean (SD) t-Value & Mean (SD) & Mean (SD) t-Value \\
\hline Roomy/cramped & $3.41(0.87)$ & 3.55 (1.02)-0.818 & $3.52(1.02)$ & $3.45(0.90)-0.414$ \\
\hline Light/dark & $3.46(1.12)$ & $3.73(1.10)-1.328$ & $3.64(1.09)$ & 3.57 (1.15)-0.881 \\
\hline Calm/restless & $3.46(0.77)$ & $3.44(0.84)-0.153$ & $3.49(1.06)$ & $3.58(0.88)-0.548$ \\
\hline Comfortable/uncomfortable & $3.75(0.75)$ & $3.78(0.87)-0.188$ & $2.27(1.09)$ & $3.70(0.82)-1.036$ \\
\hline Safe/unsafe & $3.93(0.76)$ & $4.01(0.80)-0.590$ & $4.01(0.76)$ & $3.94(0.80)-0.537$ \\
\hline Crowded/uncrowded & $2.93(0.67)$ & $2.75(0.76)-1.336$ & $2.78(0.64)$ & $2.88(0.78)-0.729$ \\
\hline Warm/cold & $3.39(0.83)$ & $3.65(1.03)-1.502$ & $3.56(1.00)$ & $3.50(0.90)-0.390$ \\
\hline Noisy/quiet & $2.31(0.97)$ & 2.49 (1.08)-0.995 & $2.37(1.09)$ & $2.42(0.99)-0.280$ \\
\hline Tidy/untidy & $3.96(0.97)$ & 3.93 (1.09)-0.164 & $4.07(1.03)$ & 3.85 (1.02)-1.181 \\
\hline
\end{tabular}

supports $\mathrm{H} 2$, which holds that there is a correlation between the bed-row layout and the level of required communication, both of which influence comfort. This finding also indicates the necessity of defining personal zones in dialysis centers. In comparing single- and doublebed layouts in terms of spatial perceptions, which are informed by elements such as comfort, illumination, and size, patients who received treatment in the single-bed layout had a more positive attitude toward the interior atmosphere (Pearson correlation coefficient $=0.198$, $\mathrm{p}=0.031$ ).

The means and t-values presented in Table 5 indicated that subjects have more positive spatial perceptions of double-bed layouts than single-bed layouts. Moreover, compared to female subjects, male subjects have more positive perceptions of single-bed layouts.

Furthermore, there is a strong (positive) linear relationship between the number of beds and the number of dialysis machines (Pearson's correlation coefficient $=0.749, p=0.00$ ). This finding demonstrates that in this study, patients are satisfied with the number of dialysis machines.

\section{Discussion}

This study analyzed how and to what extent singleand double-bed layouts in dialysis centers shape the communication (visual, verbal, and informational) and behavioral states of patients. The main part of the questionnaire included items about the physical and functional characteristics of the dialysis centers. The spaces were assessed according to their dimensions (including height), number of beds and units, aesthetics, levels of communication, and comfort by patients who were treated in single- and double-bed layouts. Patients who received treatment in the single-bed layout felt more comfortable than those treated in the double-bed layout. This finding supports $\mathrm{H} 2$ (there is a correlation between the interior layout where treatment is received and patients' communication levels). This finding also indicates the necessity of defining personal zones in dialysis centers. Regarding the comparison of single- and doublebed layouts in terms of interior atmosphere, patients who received treatment in single-bed rows had more positive attitudes towards the interior atmosphere. This outcome could indicate that although single-bed layouts provide comfort, the interaction opportunities afforded by double-bed layouts lead to more positive patient attitudes towards the atmosphere. This supports the study's overall suggestion that patients' expectations are largely shaped by opportunities for socialization and communication. In other words, patients' preference for treatment in singleor double-bed layout has to do with the accessibility of other people, rather than the treatment rooms' spatial conditions, as indicated in $\mathrm{H} 1$ (Fewer interactions occur between patients who receive treatment in a single-bed layout with staff and other patients than between patients who receive treatment in a double-bed layout).

Data on patients' psychosocial states demonstrated that communication between patients was lowly rated in singlebed layouts and was significantly lower than that of patients in double-bed layouts. The socialization characteristics of double-bed treatment rooms were statistically significantly higher, indicating that patients in a double-bed layout are more likely to communicate with staff and other patients. This finding supports $\mathrm{H} 1$ via $\mathrm{H} 2$ (There is a positive linear relationship between a double-bed layout and socialization with other patients). Therefore, communication with other patients is supported by double-bed layouts. Patient responses regarding inter-patient interaction indicates their need for communication, the presence of which 
positively impacts their psychological state. However, the results of this study do not support $\mathrm{H} 3$ (there is no statistically significant correlation between the bed-row layout and patients' feeling of familiarity). This study's results show that patients prefer to have visual, auditory, and verbal communication and interaction with healthcare staff and other patients. Thus, it can be concluded that a sense of belonging is supportive for patients. Patients feel safe when they have easy access to staff and doctors and feel relaxed when they can share their feelings with other patients.

What was interesting about patients' perceptual assessments of their treatment spaces was that they generally found their treatment spaces to be spacious, well-organized, safe, and calm. Patients were satisfied by the interior atmosphere and layouts that they experienced (although they received treatment as a group in the same area during the same period). Therefore, it can be concluded that a relationship exists between bedrow layouts, patients' perceptions of spatial quality, and patients' positive impressions of dialysis centers with a double-bed layout in their treatment rooms. Thus, the results of the study do not support $\mathrm{H} 4$ (there is no statistically significant correlation between interior bedrow layout and patients' space perceptions).

\section{Conclusions}

In conclusion, this study aimed to search the correlation between the individuals' spatial perception/preferences/ satisfaction levels and the existing spatial characteristics of the dialysis treatment units. Its findings indicate that spatial characteristics influence patients' abilities to verbally and visually communicate and that interaction with others provides psychological relief. In addition, it can be inferred from the data that bed-row layouts should enhance communication opportunities between patients and healthcare staff. Further, dialysis treatment rooms are not the only spaces in which verbal and visual communication should be prioritized; these forms of communication should be accessible in all areas of the facility, such as reception and recreational spaces, where communication is very frequent. Consequently, it would be beneficial to conduct further analyses that consider communication requirements in additional treatment rooms and that examine alternative bed-row layouts in dialysis centers. Since the spatial layout of dialysis centers has a considerable effect on patients' communication and interaction with other patients and staff and spatial perceptions, these multifactorial analyses of treatment center spaces and their psychosocial impacts could highlight design criteria particularly relevant to treatment areas.

\section{Recommendations for Future Studies}

The findings of this and similar studies could be used to develop design solutions (such as different bedrow layouts and locations of dialysis units and beds) to improve patient communication, thereby improving patient conditions. Alternative bed-row layouts could be proposed that would promote contact among patients and staff in dialysis centers. Further, patients' perceptions of bed-row layouts not analyzed in this study should be assessed, along with functional, atmospheric, or physical interior spatial designs that could support communication and interaction between the patients and doctors, staff, and other patients in dialysis centers. Likewise, alternative analyses considering communication requirements in additional treatment rooms and other bed row layouts in these healing environments should be conducted.

\section{References}

Alfonsi, E., Capolongo S., \& Buffoli, M. (2014). Evidence based design and healthcare: An unconventional approach to hospital design. Ann Ig, 26(2), 137-143.

Andrade, C., Lima, M. L., Pereira, C. R., Fornara, F., \& Bonaiuto, M. (2013). Inpatients' and outpatients' satisfaction: The mediating role of perceived quality of physical and social environment. Health and Place, 21, 122-132.

Bartley, J. M., Olmsted, R. N., \& Haas, J. (2010). Current views of health care design and construction: Practical implications for safer, cleaner environments. American Journal of Infection Control, 38(5), 1-12.

Bell, M. (1999). Rehabilitating Middle England: Integrating ecology, aesthetics, and ethics. In Williams, A. (Ed.), Therapeutic Landscapes: The dynamic between place and wellness. (pp. 15-27). Lanham: University Press of America, Inc.

Brownbridge, G., \& Fielding, D. M. (1994). Psychosocial adjustment and adherence to dialysis treatment regimes. Pediatric Nephrology, 8, 744-749.

Bordelon, T. D. (2001). Supportive relationships among hemodialysis recipients at a remodeled kidney centre. Social Work in Health Care, 33(2), 53-65.

Butler, P. (2001, November 16). Prince calls for "holistic" hospital design. The Guardian,

Chrysikou, E. (2014). Architecture for psychiatric environments: Environments and therapeutic spaces. Amsterdam: IOS Press.

Coiera, E. W., \& Tombs, V. (1998). Communication behaviors in a hospital setting: An observational study. British Medical Journal, 316, 673-676.

Connellan, K., Gaardboe, M., Damien Riggs, D., Due, C., Reinschmidt, A., \& Mustillo, L. (2013). Stressed spaces: Mental health and architecture. Journal of Health Environments Research \& Design, 6(4), 127-168.

Daft, R. (2001). Organization theory and design (7th ed.). Cincinnati: South Western Publishing Co.

Devlin, A. S. (2015) Transforming the doctor's office: Principles from evidence-based design. New York: Routledge.

Devlin, A. S., \& Arneill, A. B. (2003). Health care environments and patient outcomes. Journal of Environment and Behavior, 
35(5), 665-694.

Douglas, C. H., \& Douglas, M. R. (2004). Patient friendly hospital environments: Exploring the patients' perspective. Journal of Health Expectations, 7(1), 61-73.

Dutta, R. (2008). Influence of nursing unit layout on staff communication and interaction patterns. (Master's thesis). Retrieved from the Master of Science Bulletin of the New York Academy of Medicine. 80(4), 536-555.

Fottler, M. D., Ford, R. C., Roberts, V., Ford, E., \& Spears, J. D. (2000). Creating a healing environment: The importance of the service setting in the new consumer-oriented healthcare system. Journal of Healthcare Management, 45(2), 91-107.

Francis, S., \& Glanville, R. (2001). Building a 2020 vision: Future health care environments. (Medical Architecture Research Unit, South Bank University). London: Nuffield Trust.

Glanz, K., Rimer, B. K., \& Viswanath, K. (Eds.). (2008). Health behavior and health education: Theory, research, and practice (4th ed.). San Francisco: Jossey-Bass.

Kimmel, P. L. (2000). Psychosocial factors in adult end-stage renal disease patients treated with hemodialysis: Correlates and outcomes. American Journal of Kidney Diseases, 35(1), 132-140.

Koivula, M., Paunonen-Ilmonen, M., Tarkka, M. T., Tarkka, M., \& Laippala, P. (2002). Social support and its relation to fear and anxiety in patients awaiting coronary artery bypass grafting. Journal of Clinical Nursing, 11(5), 622-633.

Krueger, L. (2007). Wisconsin among experiences with hemodialysis (Paper submitted in partial fulfilment of the education specialist degree). University of Wisconsin-Stout, Menomonie, WI.

Lawson, B., \& Phiri M. (2000). Hospital design, room for improvement. Health Service Journal, 110(5688), 24-26.

Milburn, A., (2001). Speech at the building a better patient environment NHS/Prince's Foundation Conference, 16 November.

Pati, D., Harvey, T., \& Cason, C. (2008). Inpatient unit flexibility design characteristics of a successful flexible unit. Journal of Environment and Behavior, 40(2), 205-232.

Parker, J., \& Coiera, E. W. (2000). Improving clinical communication: A view from psychology. Journal of American Medical
Informatics Association, 7(5), 453-461.

Polaschek, N. (2003). Living on dialysis: Concerns of clients in a renal setting. Journal of Advanced Nursing, 41(1), 44-52.

Shepley, M. (2005). The healthcare environment. In J. Rollins, R. Bolig, \& C. Mahan (Eds.), Meeting children's psychosocial needs across the health-care continuum (pp. 313-349). Austin: Pro-Ed.

Shepley, M. (2006). Evidence based design and architecture. In Wagenaar, C. (Ed.), The architecture of hospitals (pp. 265267). Rotterdam: NAi Publishers.

Schreuder, E., Lebesque, L. \& Bottenheft, C. (2016). Healing environments: What design factors really matter according to patients? An exploratory analysis. Health Environments Research \& Design Journal, 10(1), 87-105.

Ulrich, R., Zimring, C., Quan, X., Joseph, A., \& Choudhary, R. (2004). The role of the physical environment in the hospital of the 21st century: A once in-a-lifetime- opportunity. Concord, MA: The Robert Wood Johnson Foundation and the Center for Health Design.

Ulrich, R. S. (2003). Creating healing environment with evidence-based design. Paper presented at the American Institute of Architects, Academy of Architecture for Health Virtual Semi-Healing Environments, Denver, CO.

Ulrich, R. S. (1999). Effects of gardens on health outcomes: Theory and research. In C. C. Marcus and M. Barnes (Eds.), Healing Gardens: Therapeutic Benefits and Design Recommendations (pp. 27-86). New York: John Wiley.

Ulrich, R. S. (1991). Effects of interior design on wellness: Theory and recent scientific research. Journal of Health Care Interior Design, 3(1), 97-109.

Ulrich, R. S. (1992). How design impacts wellness. The Healthcare Forum Journal, 35, 20-25.

Welch, J. L., \& Austin, J. K. (2001). Stressors, coping and depression in hemodialysis patients. Journal of Advanced Nursing, 33(2), 200-207.

Yıldırım, K., \& Yalcin, M. (2016). An exploratory and comparative evaluation on the spatial perception of two densities of multi-occupancy hospital rooms, Health Environments Research \& Design Journal, 9(2), 212-227. 